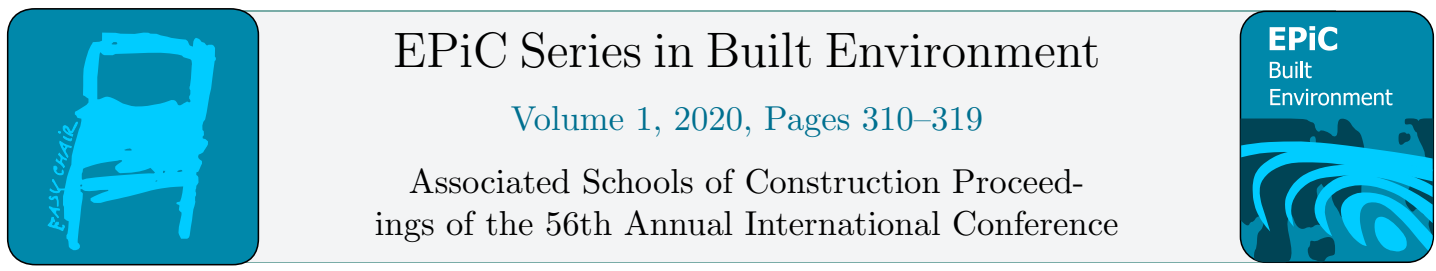

\title{
Using the Circular Economy to Manage Construction Waste
}

\author{
Riann Gonzalez \\ Holder Construction Company \\ Atlanta, GA
}

\author{
Abdol Chini, Ph.D. \\ University of Florida \\ Gainesville, FL
}

\begin{abstract}
This paper explores using the practice of a circular economy to reduce the amount of construction and demolition (C\&D) waste that is generated and going to landfills. The circular economy is a system where waste is minimized and resources are in use for as long as possible through recycling and reuse. This is in contrast to a linear economy where raw materials are extracted, used to make a product, and disposed of. This research is intended to address three issues facing the world which are increasing C\&D waste due to an increase in population and urbanism, limited natural resources, and limited land available for landfills. Buildings are major consumers of resources and producers of waste. In 2015, the built environment generated two times the amount of waste than municipal solid waste in the US. The methodology includes gathering recent C\&D waste statistics and researching case studies on the circular economy. The goal of this research is to reduce the amount of C\&D waste sent to landfills by evaluating current waste management practices and providing recommendations to make $C \& D$ waste in line with the circular economy.
\end{abstract}

Keywords: Circular Economy, C\&D waste, Landfills

\section{Introduction}

One of the largest contributors to waste in the US is the construction, demolition, and renovation of buildings and civil engineering structures. Construction and Demolition (C\&D) produced 548 million tons of waste in 2015, compared to municipal solid waste (MSW) which generated 262 million tons (U.S. EPA, 2018). MSW is all trash that consumers throw away but does not include industrial waste, hazardous waste or C\&D waste. Demolition and renovation were responsible for over $90 \%$ of the C\&D waste (518.2 million tons), leaving new construction responsible for under $10 \%$ of the waste produced, about 29.6 million tons (U.S. EPA, 2018). There are multiple consequences for C\&D waste that ends up in landfills. The construction materials can leach toxic chemicals that then trickle down into the soil and may end up in the water table.

The construction industry both requires and wastes a lot of material and resources, harming the environment through constant and unnecessary extraction and disposal. Through a mix of quantitative and qualitative research this research is summarizing steps that can be taken to make construction operation more environmentally responsible and friendly. The quantitative research involves 
gathering recent C\&D waste statistics for US and review of the current waste practices. The qualitative research includes review of case studies in Europe and states within the US that are successfully adopting or starting to adopt circular economy principles. Further qualitative research involves reviewing different policies and mandates related to construction that could be applied to reduce waste.

Traditionally, the construction industry follows a linear economy, meaning that the materials are extracted, used to make a product, and disposed of in the landfill at the end of its life. Attempts should be made to transform the industry from a linear to a circular system similar to the natural world that there is no waste. One organisms waste becomes another organism's food because there is no landfill in nature. Instead of disposing a material after one use, it can be reused or turned into another usable product. This is the concept behind the circular economy, where no materials or resources are wasted and disposed of in a landfill (Circular Economy, 2019). A circular economy emphasizes meeting societal needs of the population by using the materials that have already been extracted and manufactured while also focusing on reducing the amount of waste going into landfills to zero. This move to a circular economy can be achieved through implementing the three R's used in the sustainability industry - reduce, reuse, and recycle. These three terms are arranged in hierarchical order. Reducing the amount of waste produced from the construction industry (modular construction, accurate estimating and ordering) should be the first step so that less material and resources are used and wasted. After the amount of materials entering the waste stream is reduced, the focus should shift to reusing materials (remodeling, reusing building elements) instead of sending it to the landfill. Lastly, for the material that is left, it will be recycled and used to produce another product, such as crushed concrete resulting from demolition to be turned into aggregate to produce new concrete.

There are already examples of the circular economy being implemented and done successfully in the design and construction world. For example, Shaw Contract is a carpet manufacturer that prides itself on sustainability. Its products are used in a number of sustainable building rating systems such as LEEDv4 and WELL. Shaw is involved in the Cradle to Cradle Certified Products program that uses the principles of the circular economy to guide their product manufacturing and corporate sustainability (Cradle to Cradle, 2018). For example, when creating their carpet, Shaw uses carpet fibers that are $100 \%$ recyclable at the end of its life (Fiber, 2018).

\section{Key Issues Related to the Built Environment}

Before trying to address the issue of reducing the amount of C\&D waste in the US, it has to be understood why this topic is important and what are the influencing issues. There are three main issues that this research is intended to address: increasing C\&D waste due to an increase in population and urbanism, limited natural resources, and limited land available for landfill.

1. Increase in population and urbanism: Increasing C\&D waste generation is due to an increase in population and urbanism. The population of the Earth is expected to increase from 7.6 billion in 2017 to 9.8 billion in 2050 (World population, 2017). This trend in increasing population also applies to the US where the population is expected to increase from about 330 million in 2019 to 416.8 million in 2060 (Statista, 2018). In 2010, 80.7\% of the US population lived in urban areas (US Census Bureau, 2012). As the population continues to increase, the number of those living in urban areas is expected to increase. Increasing population and urbanism results in increasing housing and infrastructure demands which leads to an increase in construction, whether it is new construction or renovation. 
2. Limited natural resources: Humans are consuming resources at an alarming and unsustainable rate. According to the United Nations International Resource Panel, global material resource use is expected to more than double from 2015 to 2050 and resource use was almost 90 billion metric tons in 2017 worldwide (U.N. International Resource Panel, 2017). Higher-income countries, like the US are consuming resources at a rate 10 times more per person than lower-income countries. Construction is a major consumer of the world's resources, especially non-renewable resources. Natural resources that are used in the construction industry include biomass, metals, fossil fuels, and non-metallic minerals such as sand. Of the four main types of natural resources, non-metallic mineral consumption is expected to increase the most (Figure 1). This is significant because non-metallic minerals are non-renewable resources but are highly popular in the construction industry as a building material. The US National Intelligence Council predicts that the demand for steel will grow by $90 \%$ by 2030 , which also comes from non-renewable resources, although it can be recycled and reused (National Intelligence Council Report, 2013). Many of the construction materials are non-renewable during our lifetime and take thousands of years to regenerate, such as fossil fuels and non-metallic minerals. According to the US Geological Survey, only 4\% of the resources extracted in 2014 that entered the US economy were renewable (US Geological Survey, 2017).

\section{Global Material Resource Extraction}

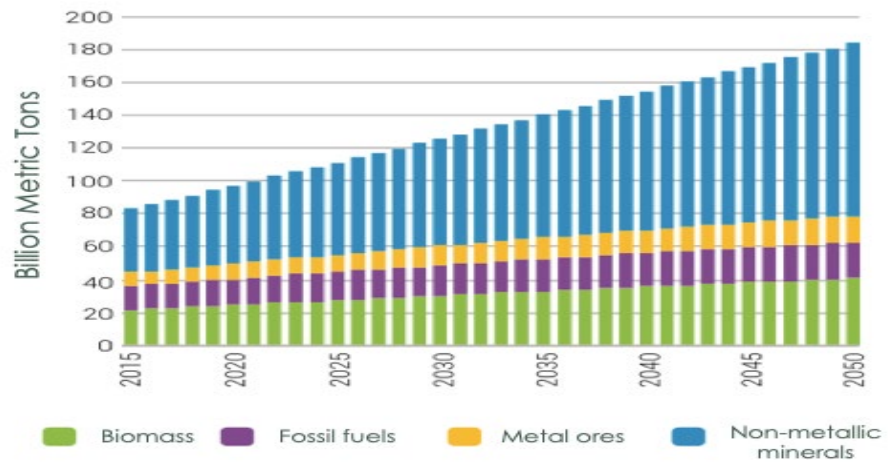

Figure 1. Global resource extraction. Adopted from the United Nations report on "Assessing Global Resource Use"

3. Limited Land available: Of the 1.9 billion acres of land that is in use in the US, urban areas account for 69.4 million acres (Merrill \& Leatherby, 2018). Urban areas have quadrupled since 1945, at an average rate of about 1 million additional acres per year (Merrill \& Leatherby, 2018). An increase in the amount of land designated urban areas leads to less land being available for other uses, such as agriculture and landfills. Half of the hundreds of millions of tons of debris produced in the US each year will end up in a landfill. There were 1,738 landfills in the US just for municipal solid waste in 2015 (U.S. EPA, 2018). In addition, there were over 1,500 active C\&D waste landfills (Powell et al., 2015).

There are negative environmental impacts associated with landfilling $C \& D$ waste and hazardous chemicals. Hazardous materials include paint that can contain lead, plywood and particle board that can contain formaldehyde, volatile organic compounds and heavy metals. A research study examined 460 thousand groundwater samples in Florida, over a period of ten years and found that there was presence of leachates from the C\&D landfills, iron being found in $91 \%$ of the samples and arsenic found in $43 \%$ of the samples (Powell et al., 2015). Also, C\&D landfills emit hydrogen sulfide which 
is a major contributor to odor and produces that "rotten egg smell." It affects human health and is a fire hazard when in great concentration, like in a landfill. When gypsum drywall becomes wet in these C\&D landfills, hydrogen sulfide is produced.

\section{C\&D Waste Statistics}

According to the 2015 fact sheet published by the US Environmental Protection Agency in 2018, C\&D waste made up a significant portion of the "non-hazardous solid waste stream (US EPA, 2018). In the U.S., 548 million tons of C\&D waste was produced in 2015. The C\&D waste was comprised of steel, drywall and plaster, asphalt shingles and concrete, wood products, brick and clay tile, and concrete. The largest material that comprised the C\&D debris was concrete, making up about $70 \%$ of the waste (Figure 2). Asphalt concrete is next at $15 \%$, followed by wood products at $7 \%$, and asphalt shingles at $3 \%$. Drywall and plasters and brick and clay tile all comprise $2 \%$ of the C\&D generation, followed finally by steel at $1 \%$.

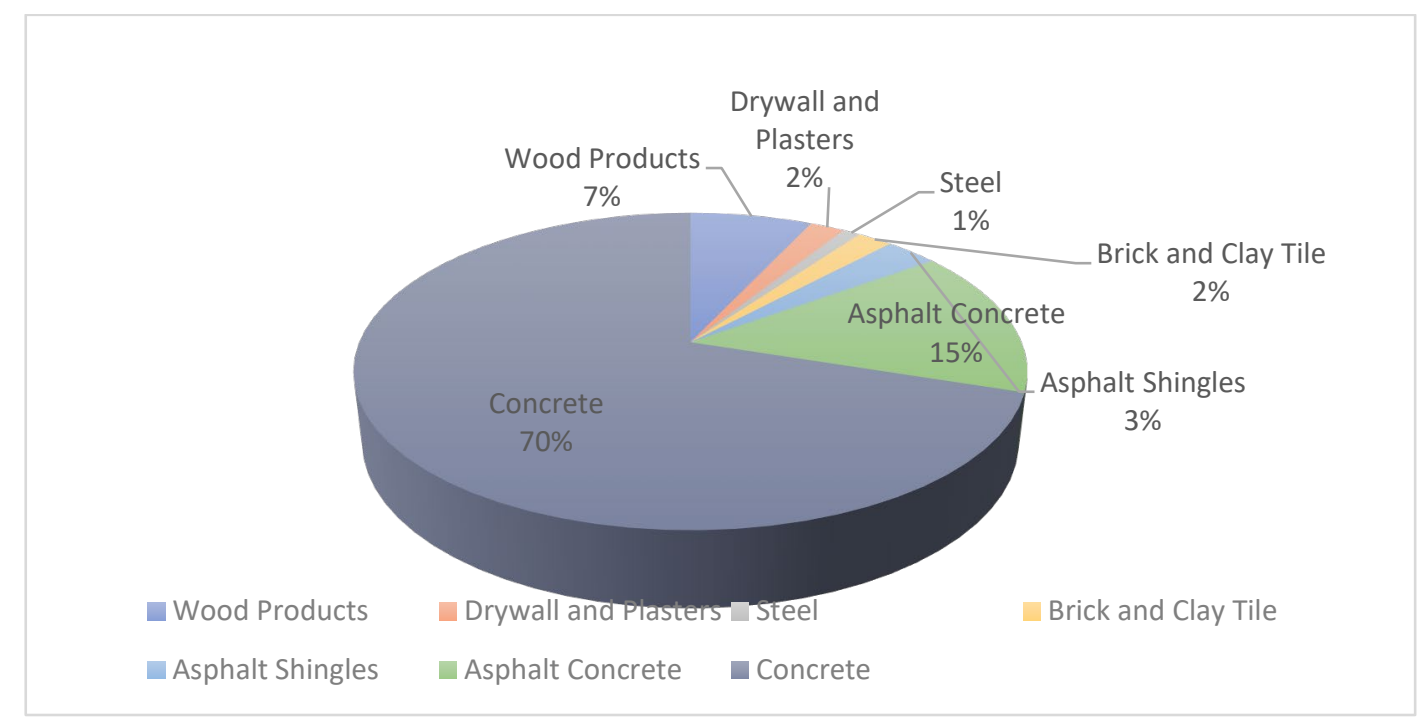

Figure 2. C\&D Waste Composition by Material (before processing). Adopted From US EPA, 2018.

The US EPA divided the C\&D waste generated by source in Table 1. There were three main sources that generated C\&D waste: buildings, roads and bridges, and "other structures." According to the 2015 data, roads and bridges generated the most C\&D waste at 242.3 million tons. Buildings ranked second at 169.1 million tons of waste generated, leaving 136.4 million tons of C\&D waste produced by "other structures". Concrete again was the most common C\&D waste material generated, making up 88.4 million tons for buildings, 158.4 million tons for roads and bridges, and 135 million tons for the "other" category.

\section{Factors Affecting C\&D waste Generation}

The amount of C\&D waste generated in the US can be attributed to increased population and urbanism and the volume of construction. Figure 3, adopted from data from the US EPA, shows a decrease in the total amount of C\&D waste generated after the 2008 recession. It also shows the trend 
in the per capita generation of waste as it peaked in the early 2000's, decreased after the recession, and then picked up again. The C\&D waste generation can be related to volume of construction, which follows population increase.

Table 1. C\&D Debris Generation by Source in 2015 (in millions of tons).

\begin{tabular}{lccc}
\hline \multicolumn{1}{c}{ Material } & Buildings & Roads and Bridges & Other \\
\hline Concrete & 88.4 & 158.4 & 135 \\
Wood Products & 37.6 & - & 1.4 \\
Drywall and Plasters & 13 & - & - \\
Steel & 4.5 & - & - \\
Brick and Clay Tile & 12.1 & - & - \\
Asphalt Shingles & 13.5 & - & - \\
Asphalt Concrete & - & 83.9 & - \\
Total & $\mathbf{1 6 9 . 1}$ & $\mathbf{2 4 2 . 3}$ & $\mathbf{1 3 6 . 4}$ \\
\hline
\end{tabular}

In order to reduce the amount of $C \& D$ debris generated, the target should be to reduce per capita consumption of materials and per capita generation of waste. This reduction could be related to the 3 R's (reduce, reuse, recycle) and a slower economy.

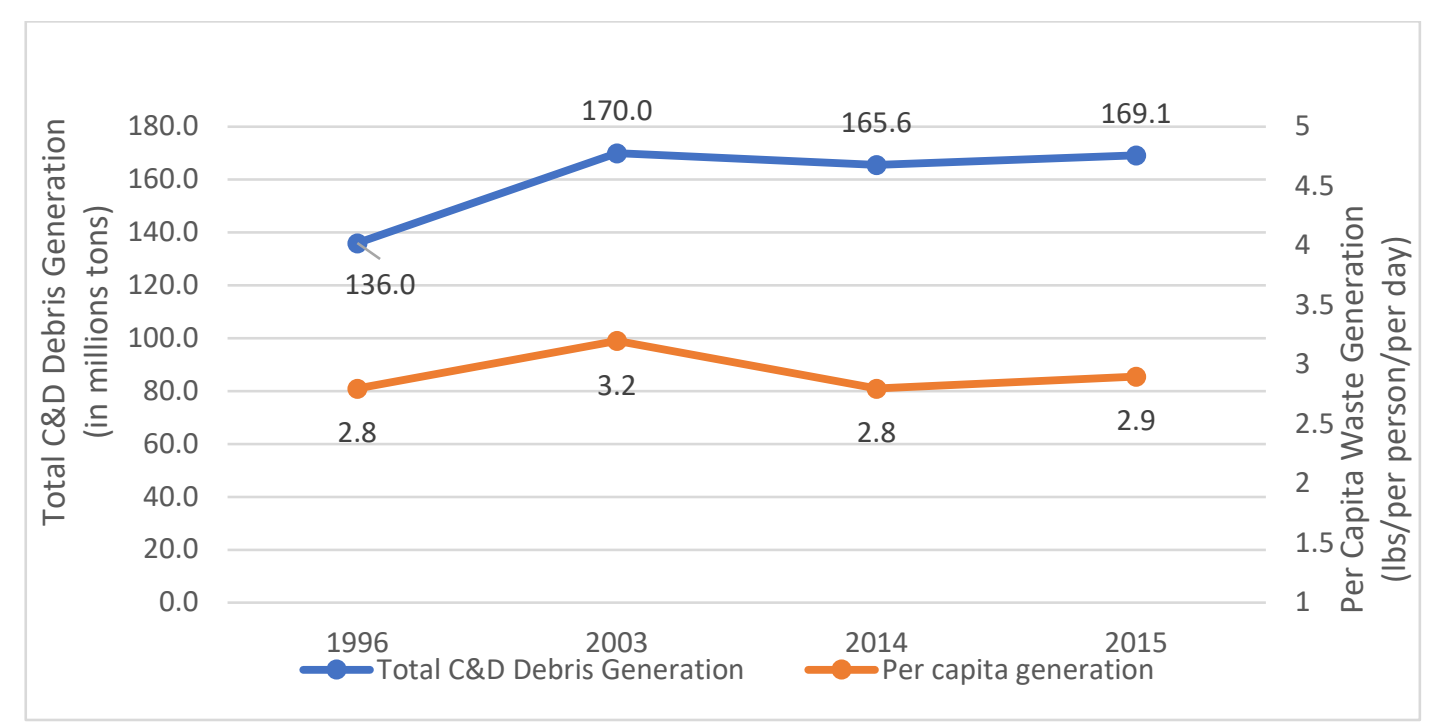

Figure 3. Total C\&D waste and Per Capita Waste Generation Trends in the US, 1996-2015.

\section{Applying the Circular Economy to C\&D Waste}

To make the greatest positive impact on the environment, building related $C \& D$ debris should be targeted because building waste makes up a significant portion of the waste stream. A plan of action for the resulting materials after their useful life must be created and implemented, which includes circular economy practices and policies. The U.S. Environmental Protection Agency has guidelines or "best practices" for reducing, reusing, and recycling C\&D materials. Their suggested circular 
economy practices include designing buildings for adaptability, disassembly and reuse, and deconstructing buildings (Best Practices, 2018).

Only concrete and steel have a recovery rate of 50 percent or above and the recovery rate for other materials is not significant. The recycling rate from building C\&D waste has the potential to greatly improve in US In order to do so, the current construction waste management practices should be adjusted to be in line with the circular economy. There are many successful cases of circular economy practices in use that promote construction waste recycling. By looking at these practices, there are recommendations that could be applied to and successfully adopted in U.S.

\section{Mandatory C\&D Waste Recycling}

The first recommendation is to make C\&D waste recycling mandatory. Recycling is a major factor of the circular economy and currently there are no federal government mandates. Mandatory C\&D waste recycling has already proven to be beneficial in Seattle. Since the adoption of the $70 \%$ C\&D debris recycling goal in 2013, Seattle has seen an increase in recycling by about 110,000 tons in 2017 (Seattle Public Utilities, 2018). The C\&D debris recycling rate in 2017 was $65.6 \%$, which is only $4.4 \%$ away from their recycling goal. Leon County in Florida, which is another place that has a high $\mathrm{C} \& \mathrm{D}$ waste recycling rate, shows that it is economically beneficial to recycle $\mathrm{C} \& \mathrm{D}$ waste because it can be sold to other industries for a profit and is therefore cheaper than landfilling where there is no profit to be made. If the federal government adopts the same mandate as Seattle, the C\&D debris recycling rate increases and the recycling companies could make a profit off of it.

\section{Mandate Using a Minimum Percentage of Materials with Recycled Content}

The federal government should also mandate that all projects use a minimum percentage of recycled products and materials during the construction of a building, similar to a LEED v3 credit where projects could earn points by using products with recycled content that made up for $10 \%$ or $20 \%$ of the total cost for materials for the project. The federal government can apply the same concept, without having to pay the registration and certification fees associated with LEED. By requiring projects to use products and materials with recycled content, this mandate will decrease the amount of virgin materials used and their impact on the environment from extraction for the project. Once the federal government has decided how to determine the minimum percentage of products and materials with recycled content the project will need to have, based on the size of the project, the contractors will then need to provide all documentation that shows they are abiding to the mandate. If a contractor fails to meet the minimum requirement, they will have to pay a high fee. This mandate could be implemented with the first recommendation as part of the new nation-wide $C \& D$ recycling ordinance.

\section{Require a Construction Waste Management Plan and Pre-Demolition Audit}

The following two recommendations go hand-in-hand and should be done before construction or demolition starts. One recommendation is to reward or require all contractors to make a construction waste management plan. This will allow the contractors to devise how the C\&D waste generated from their projects will be reused and recycled. The other suggestion is to reward or require contractors to perform a pre-demolition or pre-construction audit that identifies what $\mathrm{C} \& \mathrm{D}$ materials will be generated from the construction or demolition of their project. Both of these recommendations save time at the end of the project because the conversation of material recycling and reuse will happen before construction or demolition even begins. The process of waste recycling will be easier for the contractor because they will have already identified what materials they have to recycle and what to do with the generated material waste when the project is over, such as contacting the appropriate party 
to collect it. The contractor will be able to decide, based off what waste materials the project will generate, which type of $\mathrm{C} \& \mathrm{D}$ waste recycling is appropriate for the project whether it is single stream or source separation.

\section{Tax the Use of Virgin Materials and Landfilling C\&D Waste}

The following suggestions are financially related polices that are in line with the circular economy because they reduce the amount of virgin building materials extracted and the amount of waste that is sent to landfills. The first recommendation is to implement taxes on the use and extraction of virgin materials when alternative reused or recycled materials are available. This dissuades suppliers/manufacturer and contractors from using virgin building materials because it will be more expensive to use new materials on the project, rather than recycled or reused material. The second suggestion is to increase the tax on landfilling C\&D waste. When Denmark increased their tax on landfilling, they saw their C\&D waste recycling increase by $65 \%$.

\section{Rewarding the Use of Circular Economy Design Practices}

The following suggestions involve circular economy design practices that can reward through expedited permitting processes or tax breaks. The recommendations involve encouraging the use of durable building materials and expanding the market for reused or recycled materials. Using durable building materials, as proven in the Japan, shows that it results in reduced construction waste generation. Expanding the reused and recycled materials market will make it easier to find who to sell the building materials to after they have been identified and sorted. Also, contractors who prove that they have shared or exchanged building materials from different projects or suppliers, known as collaborative consumption, should be rewarded because the exchanged material is material that has been reused or recycled, and decreases the amount of new material that is bought. The rewards and incentives for implementing these suggestions involve providing tax breaks or advancing the permitting process. Seattle provides green building permit incentives that involves expediting building permit review and processing for projects that meets the city's green building requirements (Torgelson, 2019). Buildings that are designed for deconstruction should also be incentivized. If a designer or contractor is able to prove that the project has been designed to be deconstructed at the end of its life, then the project should be given some sort of tax break or expedited permitting process. This encourages designing buildings for deconstruction, which is a circular economy design practice, because the sooner a building has its permit, the quicker the contractor can start working on it, saving them time on the project they might have been short on before.

\section{Landfill Bans and C\&D Material Recovery Facility}

The first of the last two recommendation is to impose a landfill ban to reduce the amount of C\&D debris material waste in landfills. Landfill bans are already being imposed in few places such as Massachusetts and Seattle. Banning specific construction materials from being disposed of in the landfill will reduce the amount of $C \& D$ waste entering the landfills because it will be against the law. If contractors are found disposing of specified banned construction materials into the landfill, such as concrete, metal, and untreated and unpainted wood, they can be punished and fined high costs. Perhaps they could even lose their General Contracting license if they are repeat offenders. The ban will need to be strictly enforced and followed to make an impact on increasing recycling and reused materials. The second recommendation is to construct a material recovery facility for C\&D waste. Having a facility like this will be extremely beneficial to increase $C \& D$ waste recycling because it will be a space dedicated to receiving the construction waste and its sole purpose will be to sort and recycle building materials. The benefits and feasibility of a $C \& D$ resource recovery facility has been 
already proven in few places such as Leon County in Florida. If other municipalities are able to construct a similar recovery facility, all construction waste can be sent to the facility to be recycled, rather than to the landfills. The municipalities will be able to make a profit from all of the construction waste that is diverted from the landfill and sent to other industries and markets for money.

\section{Barriers for Implementation}

To transition the current construction waste management practices to be in line with the circular economy, there will be barriers to consider and overcome. The first possible barrier to implementing the circular economy is the access to recycled and reused materials. If one of the recommendations is to increase the use of reused and recycled material through mandates or taxes on virgin materials, there needs to be access to these materials and places or vendors readily available for contractors and owners to purchase these materials. There needs to be a market for the materials and an infrastructure in place so people know about reuse stores and places where they can go to buy or sell the reused and recycled materials. Also, the reused material vendors will need to find space to store and sell these materials. To overcome this barrier, the municipalities should have a large building material reuse store that everyone in the surrounding areas can go to. Atlanta has a non-profit store called the Lifecycle Building Center (LBC), which is a warehouse that collects reused materials, and sells them at much cheaper prices or even for free. Through this, the reuse center and store was able to divert 5 million pounds of building materials from the landfills and save the community over \$2.8 million since 2011 (Lifecycle Building Center, 2019).

The second barrier to implementation is Building Codes. Currently building codes do not address the reuse of salvaged materials or materials with recycled content. The issue of code compliance is serious because the purpose of the code is to ensure safety and if a building is found to be not code compliant, it cannot be occupied or "complete" until the issues are rectified. The code is only concerned with the building materials that are related to safety such as steel and structural concrete. Building materials have the potential to be reused and recycled for structural materials but is not currently being done so because it is unknown if the building materials will have the same structural and strength properties required by the building code. To overcome this barrier, any recycled or reused building material that has the potential to be used as a structural material, or related to safety in general, should be tested and recertified or regraded to show if it would be code compliant or not. For example, salvaged lumber has the potential to be reused for load-bearing applications, but it will need to be re-graded by qualified lumber graders to show that it is structurally sound to be used. Another way to overcome this barrier would be an amendment or update added to the building code to address the use of recycled and reused materials in building construction, like the Florida Department of Transportation (FDOT) has done with addressing the use of recycled materials in transportation projects. For example, the FDOT has specifications on the use of fly ash in the production of concrete, the use of recycled concrete aggregate as a base for new pavement, and recycled asphalt for new pavement (FDOT, 2019).

Another barrier to implementation is the perception of quality. A lot of the time, people might not be receptive to using reused and recycled material. However, just because a material is reused or recycled, it does not mean that it is of any less quality. Consumers, planners and builders would be more likely to use recycled and reused materials if the perception of these materials was improved. The two best ways to overcome negative perceptions are information availability and overcoming the perception of risk (Chini \& Bruening). Public knowledge of the benefits of recycled and reused materials needs to increase. The information is out there and accessible so as the market for these materials grow, the availability of information and public knowledge about them should increase. To overcome the perception of risk, materials and products have to show that they perform as well as or 
better than virgin products. This can be done through recertifying and testing of products to prove their performance.

\section{Conclusions}

In conclusion, the implications of aligning construction waste management practices with the circular economy will prove to be economically and environmentally beneficial. Not only will it generates income off of selling the salvaged C\&D materials but, it reduces the amount of waste materials sent to landfills. Few municipalities have implemented mandatory $C \& D$ waste recycling to commercial construction projects and have been successful in increasing their recycling rate. Incentives and rewards like expedited permitting and tax breaks for new construction can be incorporated. However, the $C \& D$ waste recycling mandate, the mandate that requires using a minimum percentage of materials with recycled content, and the landfill ban could take a few years to adopt and implement. More personnel will need to be hired by the municipalities to enforce the different mandates and check to see if contractors are recycling their $C \& D$ waste and are not landfilling building materials that are banned. Additionally, more personnel will be needed to review and approve construction waste management plans and pre-demolition and pre-construction audits. With the proper funding and implementation of these circular economy practices and recommendations, municipalities will not only increase their $C \& D$ waste recycling but will earn a profit as well by selling the recycled building materials and increasing taxes. Circular economy practices like deconstruction and recycling/reuse have already shown to be economically profitable, proving to be a win-win for the municipalities and the environment.

\section{References}

Best Practices for Reducing, Reusing, and Recycling C\&D Materials. (2018). Retrieved February 13, 2019, from https://www.epa.gov/smm/best-practices-reducing-reusing-and-recycling-construction-and-demolitionmaterials

Chini, A. R., \& Bruening, S. F. (2003). Deconstruction and Materials Reuse in the US, IJCE, Special Issue, https://www.researchgate.net/publication/228759250_Deconstruction_and_materials_reuse in the_Uni ted States

Circular Economy, (2019), Retrieved February 11, 2019, from http://ec.europa.eu/environment/circular-economy/

Cradle to Cradle Certified Products Registry, (2019). Retrieved March 3, 2019, from https://www.c2ccertified.org/products/registry

Fiber. (2018). Retrieved January 26, 2019, from https://www.shawcontract.com/en-us/products/technical/fiber

Florida Department of Transportation (FDOT). (2019). Recycled Materials. Retrieved April 22, 2019, from https://www.fdot.gov/materials/administration/resources/library/issues-trends/recycling-specs.shtm

Lifecycle Building Center. (2019). About | Lifecycle Building Center. Retrieved April 13, 2019, from https://www.lifecyclebuildingcenter.org/about

Merrill, D., \& Leatherby, L. (2018). Here's How America Uses Its Land. Retrieved February 28, 2019, from https://www.bloomberg.com/graphics/2018-us-land-use/

National Intelligence Council Report. (2013). Natural Resources in 2020, 2030, and 2040: Implications for the US (pp. 1-100, Rep.).

Powell, J. T., Jain, P., Smith, J., Townsend, T. G., \& Tolaymat, T. M. (2015). Does Disposing of C\&D debris in Unlined Landfills Impact Groundwater Quality?

Seattle Public Utilities. (2018). 2017 Recycling Rate Report (pp. 1-43, Rep.). Seattle, WA: Seattle.gov. Torgelson, N. (2019). Green Building. Retrieved April 22, 2019, from http://www.seattle.gov/sdci/permits/green-building

U.N. International Resource Panel. (2017). Assessing Global Resource Use (pp. 1-104, Rep.). United Nation Environment Programme. 
U.S. Census Bureau. (2012). 2010 Census Urban and Rural Classification and Urban Area Criteria. Retrieved February 28, 2019, from https://www.census.gov/geo/reference/ua/urban-rural-2010.html

U.S. Environmental Protection Agency, Advancing Sustainable Materials Management: 2015 Fact Sheet. (2018). Retrieved January 12, 2019, from https://www.epa.gov/sites/production/files/201807/documents $/ 2015 \mathrm{smm}$ msw factsheet $07242018 \mathrm{fnl} 508$ 002.pdf

U.S. Geological Survey. (2017). Use of Raw Materials in the U.S. From 1900 through 2014. US Department of the Interior.

World population projected to reach 9.8 billion in 2050, | UN DESA Department of Economic and Social Affairs. (2017). Retrieved January 18, 2019, from

https://www.un.org/development/desa/en/news/population/world-population-prospects-2017.html 